\title{
Damped outrigger semi-active control for seismic vibration mitigation
}

\author{
B. G. Kavyashree ${ }^{1}\left[\right.$ () Shantharam Patil ${ }^{1}\left[\right.$ ] Vidya S. Rao ${ }^{1}[0$
}

Received: 14 April 2021 / Accepted: 5 September 2021 / Published online: 19 October 2021

(c) The Author(s) 2021

\begin{abstract}
In earlier days, the only way to resist the lateral loads was to increase the lateral strength of the structure obtained by making larger cross sections and massive buildings. Structural control is one of the solutions and important topics in both points of view of security and comfort in recent years. To reduce the effect of seismic energy, one of the structural forms used is the outrigger. In recent years, supplementary devices are installed into the outrigger structure so that damping of the structure increases and helps in mitigating the vibration, this concept is called damped outrigger. In this study, a damped outrigger structure replicating St. Francis Shangri-La Place skyscraper is excited for the El-Centro earthquake, and the Kobe earthquake is numerically modeled with viscous dampers and Magneto-Rheological damper to compare its effectiveness. The finite element approach is used for the analysis of the structure using Bernoulli's Euler beam theory in modeling the core of the structure as a beam element. The state-space approach is used in modeling the structure, dampers, and controller interface in MATLAB and Simulink, then results are obtained for the peak value of displacement, acceleration, and mean values of the response of the structure. The results are discussed, which shows the significant distinction between uncontrolled and controlled responses.
\end{abstract}

Keywords Semi-active $\cdot$ Outrigger $\cdot$ Passive $\cdot$ Vibration control $\cdot$ Magneto-rheological damper

\section{List of symbols}

A System matrix

$A_{c} \quad$ Area of the core, $\mathrm{m}^{2}$

$a_{0} \quad a_{1}$, Constant correlated to frequency and inherent damping

$B \quad$ Input matrix

$b \quad$ Base length of core, $\mathrm{m}$

$C_{d} \quad$ Damping matrix, N.s/m

C Output matrix

$c_{o} \quad$ Damping at large velocity, N.s/mm

$c_{1} \quad$ Force-velocity loop non-linearity, N.s/mm

$C_{\text {pdamp }}$ Damping calculated for viscous damper considering total number of dampers, N.s/m

$C_{v i s} \quad$ Damping coefficient of the viscous damper, N.s $/ \mathrm{m}$

Shantharam Patil

patil.s@ manipal.edu

B. G. Kavyashree

kavya.shree@learner.manipal.edu

Vidya S. Rao

rao.vidya@manipal.edu

1 Manipal School of Architecture and Planning, Manipal Institute of Technology, Manipal Academy of Higher

Education, Manipal, Karnataka 576104, India
D Direct transmission matrix

$E \quad$ Input matrix as earthquake

$E_{c} \quad$ Modulus of Elasticity of concrete, $\mathrm{Pa}$

$e \quad$ Distance between the center of the core to the end of the outrigger, $\mathrm{m}$

$f \quad$ Force produced by the MR damper, $\mathrm{N}$

$g \quad$ Base length of building, $\mathrm{m}$

I Moment of inertia of core, $\mathrm{m}^{4}$

$J \quad$ Rotational inertia, $\mathrm{kgm}^{2}$

$K \quad$ Stiffness matrix, $\mathrm{N} / \mathrm{m}$

$k_{1} \quad$ Accumulator stiffness, $\mathrm{N} / \mathrm{mm}$

$k_{o} \quad$ Stiffness controlled at large velocities, N/mm

$K_{p} \quad$ Proportion constant

$L \quad$ Height of the floor, $\mathrm{m}$

$M \quad$ Mass matrix, $\mathrm{kg}$

$m \quad$ Mass of the structure per floor, $\mathrm{kg}$

$m_{f} \quad$ Mass of the floor, $\mathrm{kg} / \mathrm{m}$

$m_{c} \quad$ Mass of the core, $\mathrm{kg} / \mathrm{m}$

$N \quad$ Vector corresponds to unity for all the translational degree of freedom

$P \quad$ Lateral force, $\mathrm{N}$

$R \quad$ Location matrix of the damper

$T \quad$ Natural period, $\mathrm{s}$

$T_{i} \quad$ Integral time, $\mathrm{s}$ 
$T_{d} \quad$ Derivative time, $\mathrm{s}$

$t \quad$ Thickness of the core, $\mathrm{m}$

$U \quad$ Floor displacement, $\mathrm{m}$

$\dot{U} \quad$ Floor velocity, $\mathrm{m} / \mathrm{s}$

$\ddot{U} \quad$ Floor acceleration, $\mathrm{m} / \mathrm{s}^{2}$

$\ddot{U}_{g}(t) \quad$ Earthquake acceleration, $\mathrm{m} / \mathrm{s}^{2}$

$u \quad$ Output of the current driver to produce the required force, $\mathrm{A}$

$u(t) \quad$ Input vector

$\underline{u}(t) \quad$ Output of the controller, V

$v \quad$ Voltage to the MR damper commanded by the controller, $\mathrm{V}$

$x \quad$ Total displacement of Magneto-Rheological damper, mm

$x(t) \quad$ State vector

y Displacement within Magneto-Rheological damper, $\mathrm{mm}$

$y(t) \quad$ Output vector

$y_{a} \quad$ Angle of reference with global coordinate

$z \quad$ Evolutionary variable

$\rho_{c} \quad$ Density of concrete $\mathrm{kg} / \mathrm{m}^{3}$

$\omega \quad$ Angular frequency, $\mathrm{rad} / \mathrm{s}$

$\omega^{2} \quad$ Eigenvalues

$\varphi \quad$ Eigenvectors represent the mode shape

$\alpha \quad$ Parameter that represents a ratio of outrigger height to the total height of the core

\section{Introduction}

Structures designed by engineers serve different functions as buildings, towers, aircraft, space shuttles, bridges, roads, and water vessels. All these engineered structures including buildings are the systems that carry and/or also transmit loads. These external sources imply static load, dynamic load, blast load, and impact load to all the structures depending on the exposure of the structure. These buildings are engineered to achieve stability and strength throughout their service life and ensure occupant's safety under expected loads. The building is an integration of many structural elements like foundation, column, beam, slab, and other elements. The structural elements under the static load and dynamic load deform invariably according to the type and intensity of the load, this structural behavior is called the response of the structure. The response of the structure should be under certain limits as specified by different codes throughout the globe [1], therefore some modification has to be done in its design to withstand the uncertainty load. Earlier the stiffness and strength of the structure were increased by ductility/strength method by increasing the cross-section of the structural members that makes them heavier and bulky, intern increasing the mass of the structure will increase the force attraction, thus constrains the development of the tall structure. To overcome this constraint, external devices came into existence that could be connected to the structure to mitigate its vibrational response by making the structure flexible and tall [2]. The structural control topics involve multiple disciplines like control engineering, mechanics, material science, mathematics, and civil engineering. The different disciplines work together to get a structural control response in which mathematics provides structural load calculation, material science calculates the properties and predicts behavior under different circumstances, mechanical provides the mechanical strength, equilibrium, and stability of the structure. All the disciplines work together to discover the naturally available materials and manage to produce all the possible materials and devices that help in the simplification of the work in structural control. As the result of the advanced research, smart material devices are combined with the systems to adapt themselves to environmental changes, and those structures are called smart structures. These smart devices can themselves sense changes in the system or the environment, detect the problem in any part of the system, locate the problem, store all the data, and proceed with the appropriate action to increase system performance to preserve the integrity, serviceability, and to safeguard the structure [3]. These smart devices are developed to tackle the uncertainty in the system. In structural control, earthquakes are considered as uncertainty which has instigated huge destruction to the structure that has resulted in remarkable suffering in human beings and also a tremendous economic loss. In this case, the control of structure is the practical solution to improve the structural performance in the presence of natural hazards. In the structural engineering community, the control strategies are not completely accepted because of their stability, dependability, external power supplies, and cost-efficiency. In the design of a tall building, the significant criteria governing the dynamic response of the building are wind and seismic energy. In tall buildings, adopting a control strategy by adding robust supplementary devices is important than the conventional method of increasing the size of the element because increasing the stiffness only performs in reducing the wind load whereas it increases seismic force because of the increase in the mass [4]. The installation of supplementary control devices is more effective, light in weight, and construction cost reductions add to the structural response mitigation [5]. There are many different techniques in structural control but the principle remains the same of installing the control devices to the structural components to drastically increase the damping in the structure rather than increasing the stiffness in mitigation of structural response [6]. Semi-active dampers are considered in this study as control devices, that are most promising one because it tries to join the positive characteristics of passive devices like low energy consumption, intake of less external power but 
it has also the advantage of active devices like adaptability, optimality, flexibility in turning and monitoring.

There are different structure forms designed to maintain the stability and safety of the occupants. One of the interior structural forms called as conventional outrigger structure, where outriggers are rigidly connected to the core, and perimeter column have proven as lateral load resisting structure [7]. For the better performance of conventional outrigger, the buckling restrained braces are incorporated by [8] for single and multi-outrigger analysis, which reduce the structural response for seismic energy by energy dissipation because of high buckling restrained braces elastic stiffness $[9,10]$. These conventional outriggers are surpassed by damped outriggers where outrigger structures are modified by adding the supplementary damping devices in between the outrigger and perimeter column connection, this concept is called a damped outrigger [11-13]. The connection between the perimeter column and outrigger is not rigid as shown in Fig. 1. In many studies, damped outrigger system is considered to study its behavior under earthquake with
Fig. 1 a Elevation of the structure [24]. b Side view of the outrigger floor, damped connection between the outrigger beam and perimeter column [20]

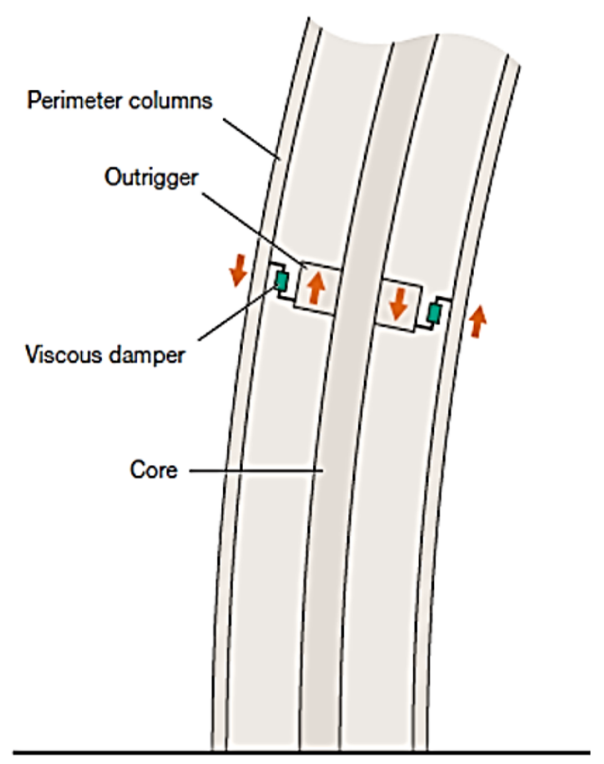

(a)

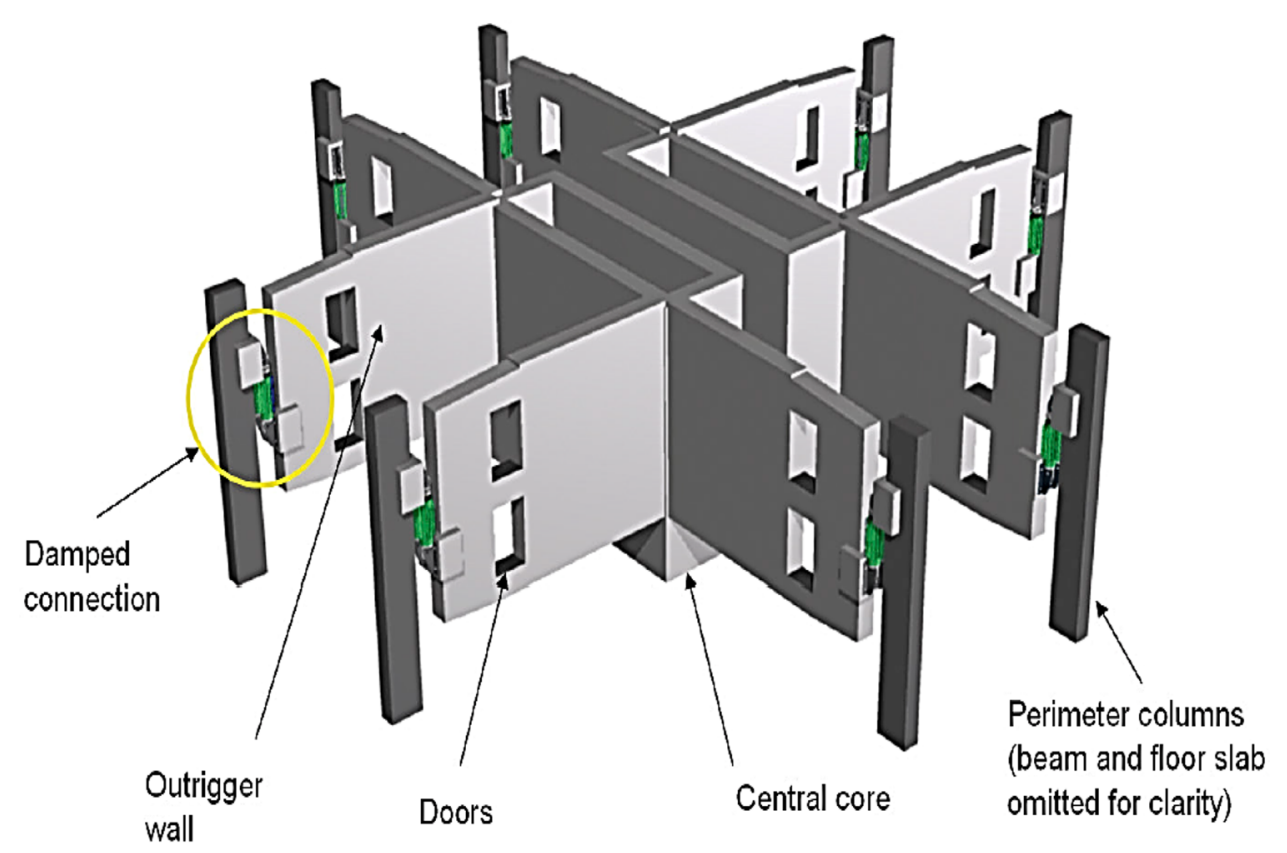

(b) 
different conditions like single damped outrigger, double damped outrigger, damping coefficient, rigidity ratios, etc., in reducing the structural response $[14,15]$.

From the literature survey done damped outrigger by adding the supplementary devices in between the outrigger and perimeter column, there will be an increment in stiffness for a small amount but the damping of the structure will increase drastically [16]. The practical application of the damped outrigger concept was proved by installing a viscous damper between the perimeter column and outrigger beam to the structure in the Philippines named St. Francis Shangri-La Place, the image of the structure is shown in Fig. 2. [17, 18]. The study has been conducted by using the viscous damper in damped outrigger along with the buckling restrained braces that show better performance in mitigating the structural response with comparing viscous damped outrigger [19]. St. Francis Shangri-La Place in the Philippines is a residential structure with a height of $210 \mathrm{~m}$ in a region of typhoon winds and UBC-97 seismic Zone 4. In real-time, fluid viscous dampers are vertically connected in the building to increase the damping of the building to reduce the vibrations as the building is located in the seismic and typhoon wind region [20].

In this study, damped outrigger structure replicating St. Francis Shangri-La Place skyscraper is considered with topical vibration control technique in it, to mitigate the response of the structure is the research gap found from the literature survey. The Bernoulli's Euler theory is considered for the modeling of the core of the structure as beam element, and the damped structure is analyzed using finite element approach. The mathematical modeling of the damped outrigger structure is formulated using the equation of structural motion [21]. Then mechanical model is transferred to linear parametric time-invariant state-space form as it is the efficient modeling form of the system that needs to be controlled. The dynamic structural system is considered as damped outrigger structure excited with the input earthquake load as the El-Centro earthquake and Kobe earthquake. The Magneto-Rheological (MR) damper is modeled according to the dynamic equations to produce the required force with passive-on mode and regulated by Proportional Integral Derivative (PID) controller in MATLAB and Simulink. A parametric time domain continuous analysis of an integrated damped outrigger modeling is done along with the MR damper as a supplementary device in it, to increase the damping of the structure against earthquake [22]. To compare the efficiency of the MR damper in controlling the damped outrigger structure as semi-active damper, a viscous damper is used as passive damper in mitigate the structural response. In this paper, a comparative study of the damped outrigger response is obtained with uncontrolled response, viscous damper controlled, passive-on mode MR damper control and MR damper controlled with PID controller. The seismic response of the structure is obtained by numerical simulation, where displacement and acceleration of the top floor of the

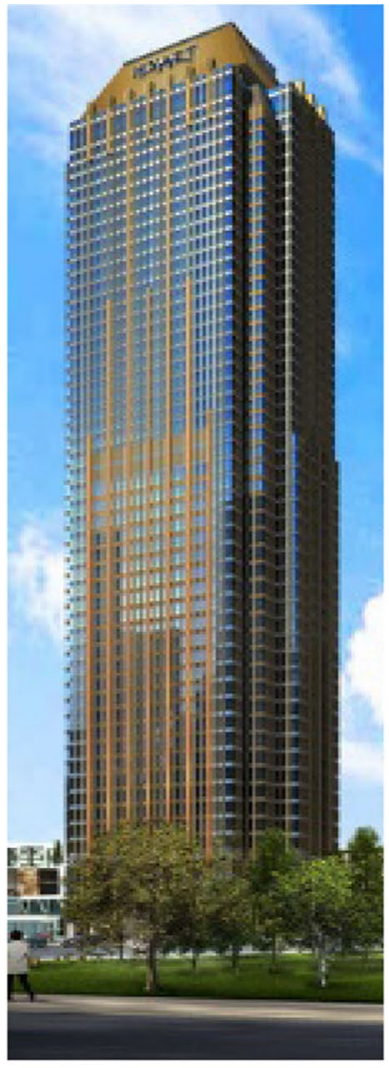

(a)

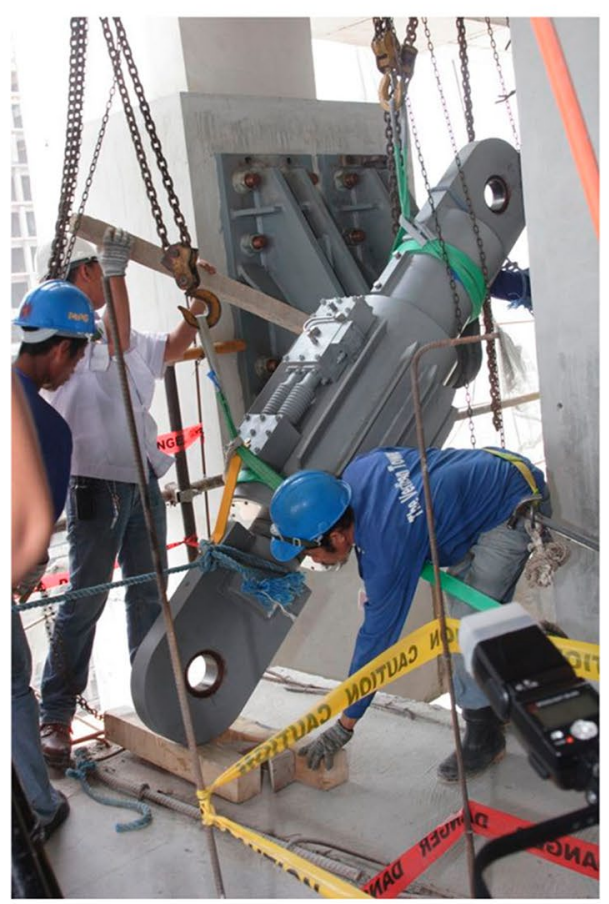

(b)

Fig. 2 a St. Francis Shangri-La Place skyscraper [20]. b Viscous damper installation in St. Francis Shangri-La Place [20] 
structure with the peak values and the mean of the structural response are discussed in the result section.

\section{Methodology}

The structural dimension considered for dynamic analysis is a 60 story rectangular building with $3.5 \mathrm{~m}$ story height pertaining to a total height $(\mathrm{H})$ of $210 \mathrm{~m}$, and base dimension (b) is $20 \mathrm{~m} \times 20 \mathrm{~m}$, located in the Philippines, that is the first building to employ the damped outrigger concept. The aspect ratio will be $(\mathrm{H} / \mathrm{b})$ as 10.5 with the floor slab of $0.15 \mathrm{~m}$. The core dimension is $12 \mathrm{~m} \mathrm{x} 12 \mathrm{~m}$ made of concrete with a thickness of $0.5 \mathrm{~m}$. The structure considered in this study contains total of sixteen viscous dampers in which eight dampers control the response each in the two orthogonal directions. As we know the outrigger is the stiff arm that connects the core to the perimeter column which spans $4 \mathrm{~m}$, and there will be two outriggers in each direction summing up to eight outriggers in four directions as shown in Fig. 3 (a) [23]. The distance between the center of the core to the end of the outrigger $(e)$ is $12 \mathrm{~m}$ in length as shown in Fig. 3b. There are four columns in each direction two supporting the outrigger, and the other two at the ends made up of concrete will be participating in resisting the lateral load. The assumption considered in this study is that the building core is considered as a cantilever beam with constant cross-section area throughout, and stiffness is considered as uniform throughout. Outriggers are considered to have a rigid connection to the core, and thus, the core and outrigger rotate the same amount. Outriggers are located at the distance of $H$ (一 - parameter that represents a ratio of outrigger height to the total height of the core) from the ground, and it is assumed as massless. The columns are considered to have a pinned connection to the ground. For static analysis, the load is considered as quasi-static load uniform throughout the height of the building. The unidirectional excitation is considered in this study. The El-Centro earthquake at Imperial Valley occurred in 1940 and the Kobe earthquake at Amagasaki occurred in 1995 are the two earthquake records considered in the study. The initial steps in modeling outrigger structure are defining material property and sectional property including the moment of inertia, Young's modulus, and area of the section, building overall stiffness matrix, and overall mass matrix developed according to finite element modeling. Outrigger location is considered to be the 42nd floor as it is found as an optimum location that provides a minimum response of the structure [18, 24].

The dimension of the structure with all the details considered in the calculation of the structural parameter is presented [25],

Modulus of Elasticity of concrete, $E_{c}=3.6 * 10^{10} \mathrm{~Pa}$.

The density of concrete, $\rho_{c}=2400 \mathrm{~kg} / \mathrm{m}^{3}$.

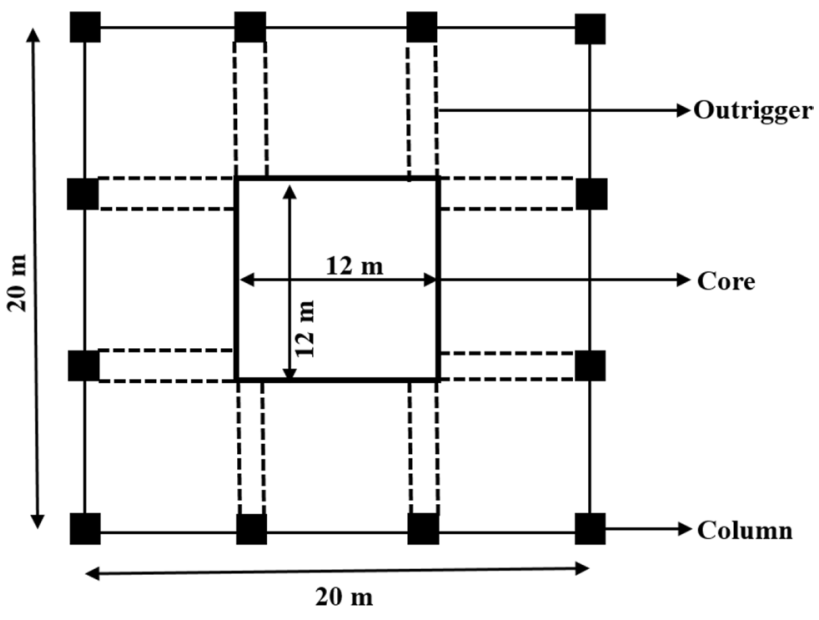

(a)

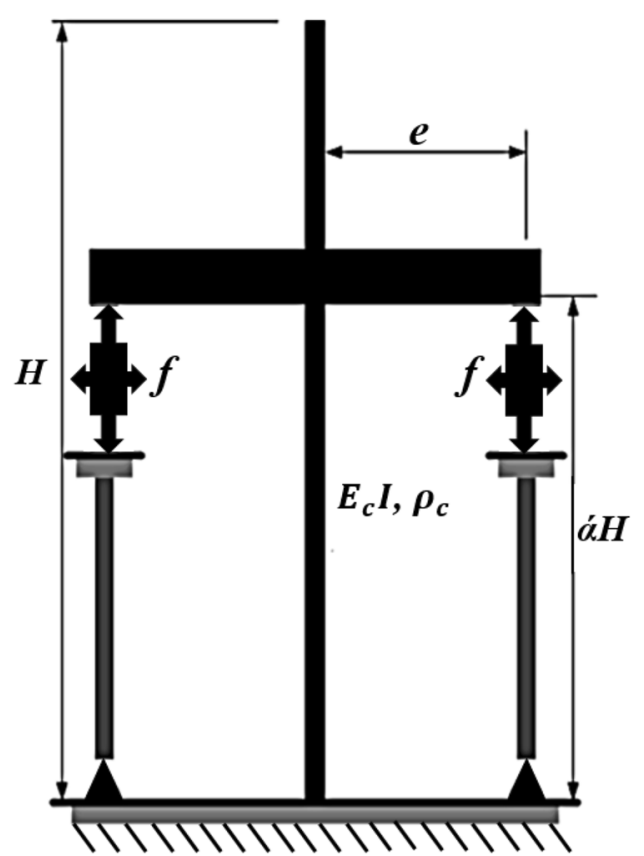

(b)

Fig. 3 (a) Top plan of the building. (b) Elevation of the building

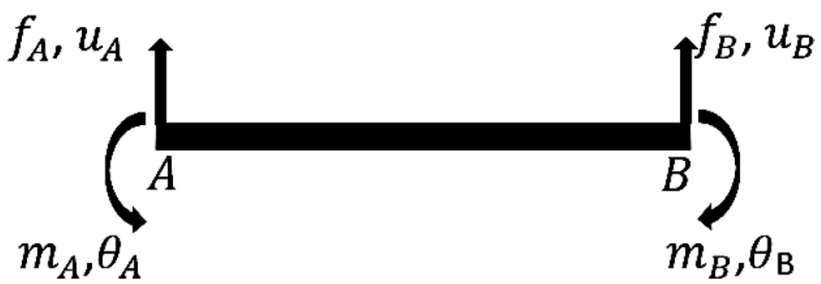

Fig. 4 Beam element with an active degree of freedom 
Base length of building, $g=20 \mathrm{~m}$

Base length of core, $b=12 \mathrm{~m}$

Thickness of the core, $t=0.5 \mathrm{~m}$

Floor height, $L=3.5 \mathrm{~m}$

Area of the core, $A_{c}=b^{2}-(b-2 t)^{2}=12^{2}-(12-(2 * 0.5))^{2}=23$ $\mathrm{m}^{2}$.

Moment of inertia of core, $I=\left(b^{4}-(b-2 t)^{4}\right) / 12=\left(12^{4}-(12-(2 * 0.5))^{4}\right) / 12=507.91 \mathrm{~m}^{4}$.

Distributed mass along the height of the structure per meter $=$ Mass of the floor $\left(m_{f}\right)+$ Mass of the core $\left(m_{c}\right)=90308.6 \mathrm{~kg} / \mathrm{m}$.

$m=$ Mass of the structure per floor $=90308.6 \times 3.5=316080.1 \mathrm{~kg}$.

$J=$ Rotational inertia $=\left(\frac{1}{12}\right) *\left\{\left[b^{2} * L * \rho_{c} *\right.\right.$ $\left.\left.\left(b^{2}+L^{2}\right)\right]-\left[(b-2 t)^{2} * L * \rho_{c} *\left((b-2 t)^{2}+L^{2}\right)\right]\right\}=$ $\left(\frac{1}{12}\right) *\left\{\left[12^{2} * 3.5 * 2400 *\left(12^{2}+3.5^{2}\right)\right]-\left[(12-(2 * 0.5))^{2}\right.\right.$ $\left.\left.* 3.5 * 2400 *\left((12-(2 * 0.5))^{2}+3.5^{2}\right)\right]\right\}=4463725$ $\mathrm{kgm}^{2}$.

\section{Outrigger structural properties}

The structure is considered to have an identical mass throughout the height as $M_{1}=M_{2}=\cdots=M_{60}=m$. The total mass of the building obtained is equal to the mass of the core and mass of the concrete core of one floor. The rotational inertia is also equal through the full height of the building. $J_{1}=J_{2}=\cdots=J_{60}=J$. The overall mass matrix $M$ is given in the Eq. 2. The equation of motion of the structure is given,

$M \ddot{U}+C_{d} \dot{U}+K U=P$

In the above equation, $M$ represents the mass matrix, $C_{d}$ represents the damping matrix, $K$ represents the stiffness matrix of the structure, $P$ represents the lateral force, $U$ represents the floor displacement, $\dot{U}$ represents the floor velocity, and $\ddot{U}$ represents the floor acceleration, respectively.

$M=\left[\begin{array}{cccccc}M_{1} & & & & & \\ & J_{1} & & & 0 & \\ & & \ddots & & & \\ & & & \ddots & & \\ & 0 & & & M_{60} & \\ & & & & & J_{60}\end{array}\right]$
Outrigger structure is modeled as bar elements for columns and beam elements for the core of the structure. The assumption considered is that there are no axial forces for the beam element, but moment and vertical force in each of the node is considered to give rotation and displacement as shown in Fig. 4.

The stiffness matrix can be divided into four parts based on the nodes for the convince of expression for the overall stiffness matrix $K$. The stiffness matrix of the member which is considered as beam element for core and bar element for the column is given by,

$k_{A A}=\left[\begin{array}{cc}\left(\frac{A_{c} E_{c}}{L} \sin ^{2} y_{a}+\frac{12 E_{c} I}{L^{3}} \cos ^{2} y_{a}\right) & \frac{6 E_{c} I}{L^{2}} \cos y_{a} \\ \frac{6 E_{c} I}{L^{2}} \cos y_{a} & \frac{4 E_{c} I}{L}\end{array}\right]$

$k_{A B}=\left[\begin{array}{cc}\left(-\frac{A_{c} E_{c}}{L} \sin ^{2} y_{a}+\frac{12 E_{c} I}{L^{3}} \cos ^{2} y_{a}\right) & \frac{6 E_{c} I}{L^{2}} \cos y_{a} \\ -\frac{6 E_{c} I}{L^{2}} \cos y_{a} & \frac{2 E_{c} I}{L}\end{array}\right]$

$k_{B A}=\left[\begin{array}{cc}\left(-\frac{A_{c} E_{c}}{L} \sin ^{2} y_{a}+\frac{12 E_{c} I}{L^{3}} \cos ^{2} y_{a}\right) & -\frac{6 E_{c} I}{L^{2}} \cos y_{a} \\ \frac{6 E_{c} I}{L^{2}} \cos y_{a} & \frac{2 E_{c} I}{L}\end{array}\right]$

$k_{B B}=\left[\begin{array}{cc}\left(\frac{A_{c} E_{c}}{L} \sin ^{2} y_{a}+\frac{12 E_{c} I}{L^{3}} \cos ^{2} y_{a}\right) & -\frac{6 E_{c} I}{L^{2}} \cos y_{a} \\ -\frac{6 E_{c} I}{L^{2}} \cos y_{a} & \frac{4 E_{c} I}{L}\end{array}\right]$

From the Eqs. 3-6, $A_{c}$ represents the area of the core, $E_{c}$ represents young's modulus, $I$ is a moment of inertia, $L$ is the height of the floor, and $y_{a}$ angle of reference with global coordinate.

To build the final stiffness matrix of the outrigger structure, initially the stiffness matrix of the structure without considering the outrigger has to be formed, followed by adding the spring stiffness to the matrix at the location of the outrigger level. The direct stiffness method is considered to get the final stiffness matrix [26]. The building in this study has 60 floors, where the single node is considered to have two degrees of freedom constituting 120 degrees of freedom as stated in Eq. 7, the dimension of the global stiffness matrix $K$ is $120 \times 120$, where $u_{1} . . u_{60}$ and $\theta_{1} . . \theta_{60}$ are deflection and rotation of the element.

$$
K=\left[\begin{array}{cccccc}
k_{1 B B}+k_{1 A A} & k_{1 A B} & & & & \\
k_{1 B A} & k_{1 B B}+k_{2 A A} & k_{2 A B} & & 0 & \\
& k_{2 B A} & k_{2 B B}+k_{3 A A} & & & \\
& & & \ddots & k_{58 A B} & \\
& 0 & & k_{58 B A} & k_{58 B B}+k_{59 A A} & k_{59 A B} \\
& & & & k_{59 B A} & k_{59 B B}+k_{60 A A}
\end{array}\right]\left[\begin{array}{c}
u_{1} \\
\theta_{1} \\
\vdots \\
\vdots \\
u_{60} \\
\theta_{60}
\end{array}\right]
$$


The structure with the outrigger arm is considered as spring, and the rotational stiffness of the spring is added at the location of the outrigger arm. The rotational stiffness of the spring is added to the node representing the outrigger location.

When the structural mass and stiffness are known, the mode shape and Eigen valves are found by Eigen valve problem solution, where frequency and natural period of the building are calculated as shown in Eqs. 8-9,

$K \varphi=\omega^{2} M \varphi$

$\varphi$-Eigenvectors represent the mode shape.

$\omega^{2}$-Eigen values.

$\omega$-Angular frequency ( $\mathrm{rad} / \mathrm{s})$.

The natural period is inverse of frequency and can be obtained as follows,

$T=\frac{1}{\text { frequency }}=\frac{2 \pi}{\omega}$

The damping of the structure is calculated based on the concept of Rayleigh damping. There is an assumption in Rayleigh damping that stiffness and mass of the structure are proportional to its damping. The equation connecting the stiffness, damping, and mass of the structure is,

$C_{d}=a_{0} M+a_{1} K$

$C_{d^{-}}$- Damping of the structure (N. s/ m).

$M$ - Mass of the structure $(\mathrm{kg})$.

$K$ - Stiffness of the structure $(\mathrm{N} / \mathrm{m})$.

This $a_{0}$ and $a_{1}$ in the Eqs.11-12 are related to damping ratio and angular frequency of the structure for any two different modes. The inherent damping considered as $2 \%$ for each mode, and the unit of $a_{0}$ is $\left(\mathrm{s}^{-1}\right)$ and $a_{1}$ is (s).

$a_{0}=\zeta\left(\frac{2 \omega_{i} \omega_{j}}{\omega_{i}+\omega_{j}}\right)$

$a_{1}=\zeta\left(\frac{2}{\omega_{i}+\omega_{j}}\right)$

In Rayleigh damping, the initial natural frequency can be selected as reference frequency to calculate $a_{0}$ and $a_{1}$, as considered in the traditional method to obtain damping of the structural.

\section{Viscous damper}

Viscous dampers are passive type device which dissipates energy with structural motion as input that has a piston, orifices, and seals arranged to obtain the forces with the flow of liquid within them. The force produced by the damper will be the velocity function between the ends of the device.
For the multi-degree of freedom model based on finite element modeling, the supplement damping of viscous damper considered in the structure is given as,

$C_{\text {pdamp }}=\left\{8 * C_{v i s} * e^{2}\right\}$

$C_{p d a m p}$-Damping calculated for viscous damper considering total number of dampers and distance, $C_{v i s}$-Damping coefficient of the viscous damper, $e$ - the distance between the center of the core to the end of the outrigger. $C_{p d a m p}$ is added to the rotational degree of freedom at the outrigger floor. Eight dampers are considered in each of the two orthogonal directions, similar to the existing configuration in the St. Francis Shangri-La Place. From the literature, the damping coefficient $\left(C_{v i s}\right)$ in the range of 5-800 M.N.s $/ \mathrm{m}$ is chosen to find an efficient coefficient by trial and error method, and in this study 90 M.N.s/m as the designed damping coefficient [16]. The damping of the passive device is added to the system matrix in state-space modeling of the damped outrigger structural modeling as represented in the Eq. 14.

$A=\left[\begin{array}{cc}0 & I \\ -[M]^{-1}[K] & -[M]^{-1}\left[C+C_{\text {pdamp }}\right]\end{array}\right]_{240 X 240}$

\section{Magneto-rheological damper performance and modeling}

In the construction industry, the MR damper is considered a capable device in reducing the structural response because of the property of MR fluid. MR dampers are semi-active devices because of their flexible characteristics of active dampers and the dependability of passive dampers. These dampers can work with the minimum amount of energy, that is even with the battery power, it has a capacity of high force production, workability in a wide range of temperature, etc. This behavior of the MR damper is because of MR fluid properties of an instant transformation of its states [27]. MR fluids are the magnetic analogs of electrorheological fluids that are of micron sized, magnetically polarized particle which is spread in mineral or silicon oil in between different chambers through a small orifice in the piston. Electrical circuit in the form of coil winding is introduced in the device, that in the presence of the current produces the magnetic field. This magnetic field in turn participates in the activation of the carrier magnetic particles in the fluid to form a chain that changes the fluid from viscous to semi-solid state to produce yield strength, hence exhibits the damping forces with altering inter-particle attraction continuously to produce the force. Consequently, the resistance of the damper can be continuously changed in real-time by modulating electrical current that permits continuous control 


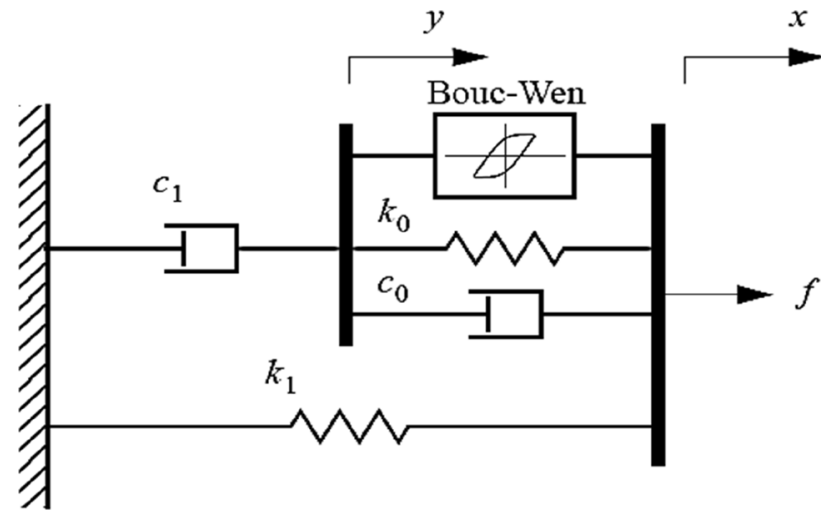

Fig. 5 Mechanical model of MR damper [24]

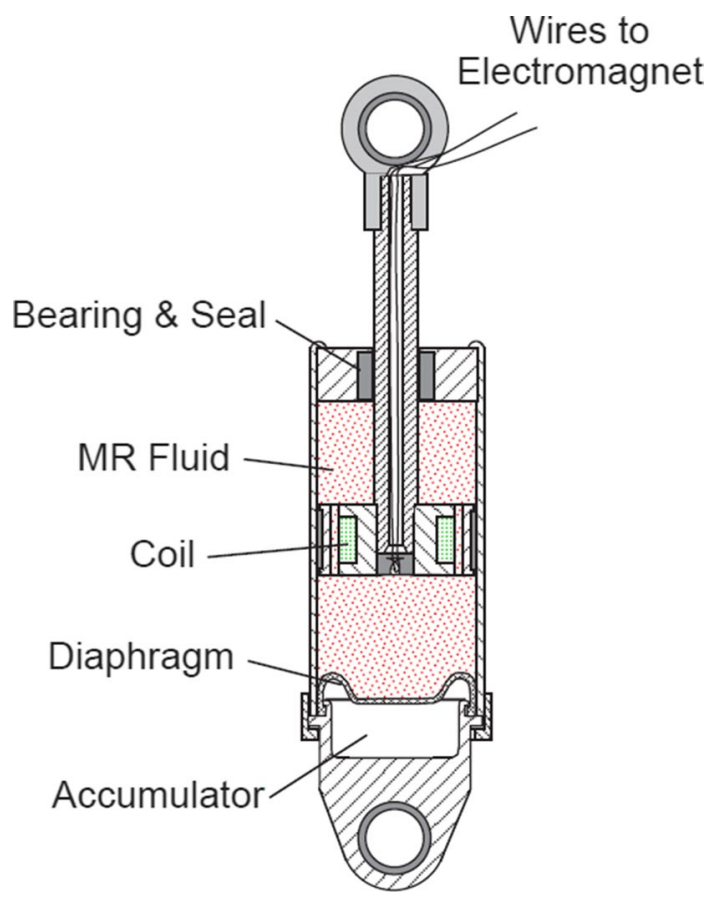

Fig. 6 Schematic diagram of MR damper [30]

of the fluid properties in the damper to produce the required force by the system [24].

The mechanical model and schematic diagram of the MR damper is shown in Figs. 5 and 6, and the force output formulas of the MR damper are shown in the Eqs. 15-21, [28]. The applied force predicted by this model is given by,

$f=\alpha z+c_{o}(\dot{x}-\dot{y})+k_{o}(x-y)+k_{1}(x)$

where the evolutionary variable is z governed by

$\dot{z}=-\gamma|\dot{x}-\dot{y}| z|z|^{n-1}-\beta(\dot{x}-\dot{y})|z|^{n}+a(\dot{x}-\dot{y})$ $\dot{y}=\frac{1}{\left(c_{o}+c_{1}\right)} \times\left\{\alpha z+c_{o} \dot{x} \dot{+} k_{o}(x-y)\right\}$

In the above formulas, $k_{1}$ and $k_{o}$ are accumulator stiffness and stiffness controlled at large velocities, $c_{o}$ and $c_{1}$ are damping at large velocity and force-velocity loop nonlinearity [29]. $\gamma$ and $\beta$ are constants, and the equations for the current driver are represented further,

$\alpha=\alpha(u)=\alpha_{a}+\alpha_{b} u$

$a=a(u)=a_{a}+a_{b} u$

$c_{o}=c_{o}(u)=c_{o a}+c_{o b} u$

$\dot{u}=-\eta(u-v)$

From the above equations, $v$ is the voltage to the MR damper commanded by the controller, and $u$ is the output of the current driver to produce the required force.

Accordingly, the MR damper is formulated, and the model is rigged up in Simulink which is shown in Fig. 7.

There is an assumption made in the MR damper to obtain force to match the capacity of the building, i.e.,: the MR damper force originally got is multiplied by 2500 to get the required force by the structure, and it is scaled as $25.4 \mathrm{~mm}$ is equal to $1 \mathrm{~m}$ in the model of damped outrigger structure [24].

MR damper acts as a passive damper when constant voltage and displacement are fed into the input of the damper. The Magneto-rheological damper when fed with the constant voltage that is $5 \mathrm{~V}$ it acts as a passive-on mode damper. The MR damper is considered in this study in passive-on mode and MR structured with PID controller [30].

\section{State-space representation}

State-space is one of the efficient modeling forms that give the input and output behavior of the system with its internal structural description of a dynamic system that is required to be controlled. Systematic analysis and synthesis of higher system, the nonlinear system can be modeled using statespace. The equation of the State-space is the set of order systems without truncation of system dynamics, and it is a good system for the representation of a multi-input multioutput system. The representation of a continuous, discrete system, time-varying, time-invariant system, and the combinations can be represented by the state-space method. The structural motion equation of controlled structure along with the earthquake is given in Eq. 22, 


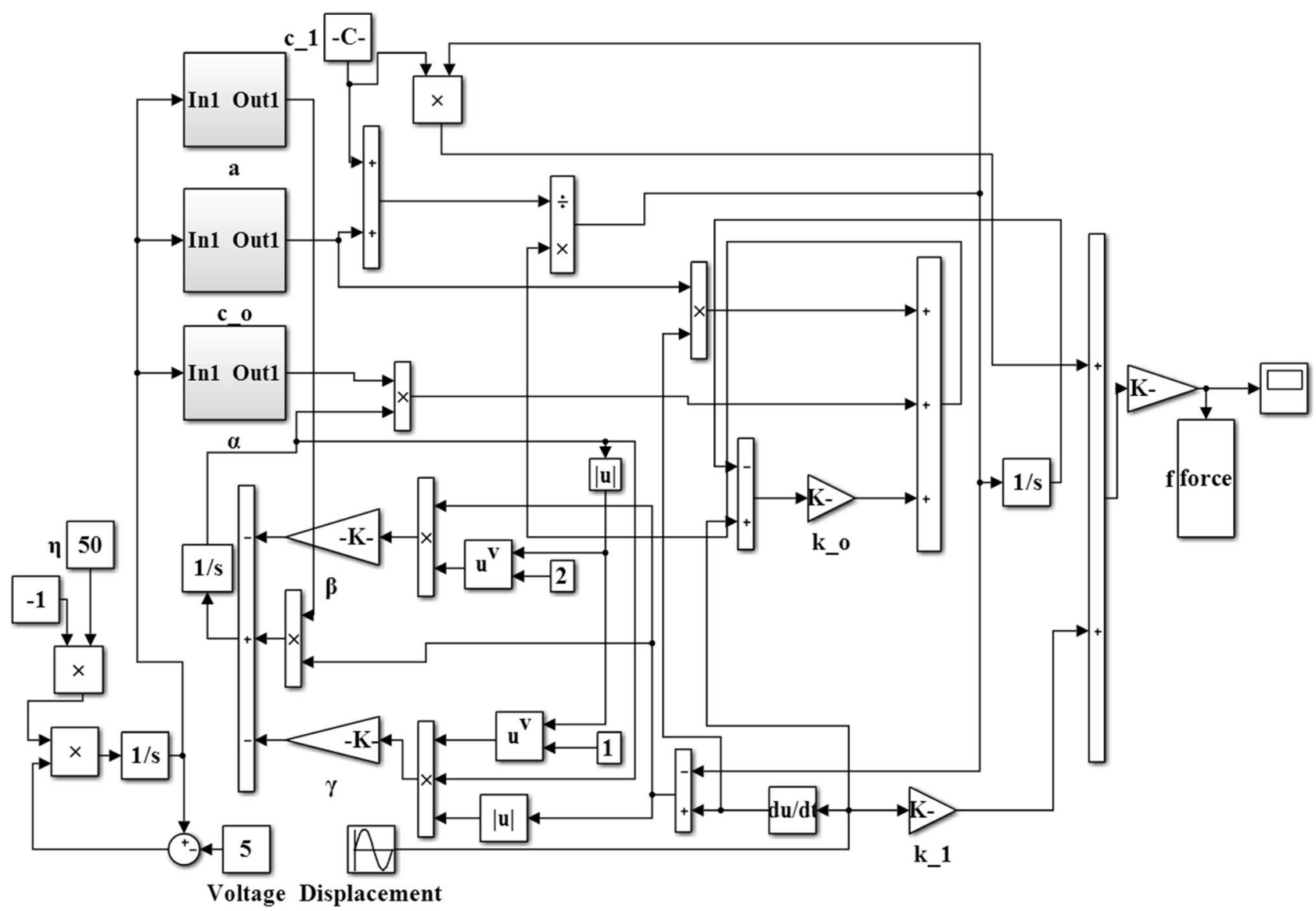

Fig. 7 Simulink model of MR damper (Created by Author)

$M \ddot{U}(t)+C_{d} \dot{U}(t)+K U(t)=R f(t)-M N \ddot{U}_{g}(t)$

In the above equation, $M$ represents the mass matrix, $C_{d}$ represents the damping matrix, $K$ represents the stiffness matrix of the structure, $U(t)$ represents the floor displacement, $\dot{U}(t)$ represents the floor velocity, and $\ddot{U}(t)$ represents the floor acceleration, respectively. $f(t)$ is MR damper force, $R_{120 X 1}$ is the location matrix of the damper, $N_{120 X 1}$ is column vector with alternate ones and zeros, corresponds to unity for all the translational degree of freedom, and $\ddot{U}_{g}(t)$ is earthquake acceleration.

For the uncontrolled case without the damper, the force produced $f$ is zero, and for the controlled case, the force produced is calculated from the MR damper.

To model the benchmark outrigger problem in Simulink, the general expression of the structural system is converted to the state-space formulation. To express the dynamic behavior of multi-degree of freedom system, a linear second-order differential equation is written in matrix form in Eq. 23, assuming the equation of the motion of the structure is linearly invariantly ([M], $[\mathrm{C}]$, and $[\mathrm{K}]$ are constant) observable system with the MR damper.

$[M]\{\ddot{U}(t)\}+\left[C_{d}\right]\{\dot{U(t)}\}+[K]\{U(t)\}=[R]\{f(t)\}-[M][N]\left\{\ddot{U}_{g}(t)\right\}$

The continuous time-invariant state-space equation is a set of the linear differential equation, and a set of the algebraic equation is given in the standard form is as follows,

$\dot{\mathrm{x}}(t)=A \mathrm{x}(t)+B \mathrm{u}(t)+E \ddot{U}_{g}(t)$

$\mathrm{y}(t)=C \mathrm{x}(t)+D \mathrm{u}(t)$

Here $\mathrm{x}(t)$ is the state vector, $\underline{u}(t)$ is the input vector, and $y(t)$ is the output vector. Here $A$ is system matrix, $B$ and $E$ are input matrix, $C$ is output matrix, and $\mathrm{D}$ is direct transmission matrix and are represented in Fig. 8. 


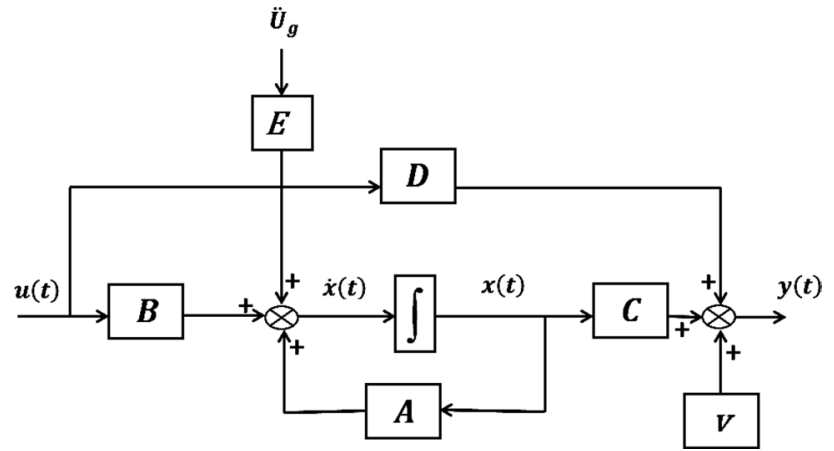

Fig. 8 State-space representation of St. Francis Shangri-La Place (Outrigger structural system) (Created by Author)

State vector, $\mathrm{x}(t)=\left\{\begin{array}{c}\mathrm{x}_{1} \\ \mathrm{x}_{2} \\ \vdots \\ \vdots \\ \mathrm{x}_{239} \\ \mathrm{x}_{240}\end{array}\right\}_{240 \times 1}=\left\{\begin{array}{c}U_{1} \\ \vdots \\ U_{120} \\ \dot{U}_{1} \\ \vdots \\ \dot{U}_{120}\end{array}\right\}_{240 \times 1}$

Input vector $\underline{u}(t)=\left\{\begin{array}{l}\underline{u}_{1} \\ \underline{u}_{2}\end{array}\right\}_{2 X 1}=\left\{\begin{array}{l}\ddot{U}_{g} \\ f\end{array}\right\}_{2 X 1}$

Iutput vector, $y(t)=\left\{\begin{array}{c}y \\ 1 \\ \vdots \\ y_{120}\end{array}\right\}_{120 X 1}=\left\{\begin{array}{c}U \\ 1 \\ \vdots \\ U \\ 120\end{array}\right\}_{120 X 1}$

Here the state vector $\mathrm{x}(t)$ of dimension $\mathrm{n} \times 1$, the input vector $u(t)$ of dimension $\mathrm{m} \times 1$ and the output vector $y(t)$ of dimension $\mathrm{p} \times 1$. Here $A$ represents system matrix of dimension $\mathrm{n} \times \mathrm{n}, B$ represents input matrix of dimension $\mathrm{n} \mathrm{m}, C$ represents output matrix of dimension $\mathrm{p} \mathrm{x} \mathrm{n}$, and $\mathrm{D}$ represents direct transmission matrix of dimension $\mathrm{p} \mathrm{x} \mathrm{m}$.

$$
\begin{aligned}
& A=\left[\begin{array}{cc}
0 & I \\
-[M]^{-1}[K] & -[M]^{-1}\left[C_{d}\right]
\end{array}\right]_{240 \times 240} \\
& B=\left[\begin{array}{c}
0 \\
{[M]^{-1}[R]}
\end{array}\right]_{240 X 1} \\
& E=\left[\begin{array}{c}
0 \\
-N
\end{array}\right]_{240 X 1} \\
& C=\left[-[M]^{-1}[K]-[M]^{-1}\left[C_{d}\right]\right]_{120 X 240}
\end{aligned}
$$

$D=\left[[M]^{-1}[R] 0\right]_{120 X 2}$

\section{Proportional integral derivative (PID) controller}

PID controller is the oldest and widest used control system in the industry. In this study, the PID controller is used in the feedback loop, and it is tuned by trial and error method to command voltage required by the MR damper. Equation 34 shows the formula of PID, in which $\hat{e}(t)$ is the error calculated, $u(t)$ is the output of the controller as voltage, $K_{p}$ is the proportion constant, $T_{i}$ is integral time, and $T_{d}$ is derivative time. In this study, PID controller is interfaced with the MR damper and damped outrigger structural model. This is simulated in MATLAB and Simulink [31, 32].

$\underset{\sim}{u}(t)=K_{p} \times\left\{-:(t)+\left(\frac{1}{T_{i}} \times \int_{0}^{t}-:(t) \times d(t)\right)+\left(T_{d} \times \frac{d-:(t)}{d t}\right)\right\}$

\section{Results and discussions}

By adopting the methodology discussed in this paper, the outrigger structural response in the presence and absence of the controller is obtained. The seismic response of the damped outrigger structure is plotted for two different earthquakes in this study to know the performance of the structure in the absence and presence of the damper. Displacement of the top floor of the damped outrigger structure for El-Centro and Kobe earthquake considering uncontrolled structure, for the structure with viscous damper, MR damper in passiveon mode (i.e., maximum constant voltage of $5 \mathrm{~V}$ is feed to damper) and MR damper with PID controller are shown in Figs. 9 and 10, respectively.

The acceleration of the top floor of the damped outrigger structure for El-Centro and Kobe earthquake considering uncontrolled structure, for the structure with viscous damper, MR damper in passive-on mode (i.e., maximum constant voltage of $5 \mathrm{~V}$ is feed to damper) and MR damper with PID controller are shown in Figs. 11 and 12, respectively.

Figures 13 and 14 represent the acceleration profile of top floor for El-Centro and Kobe earthquake, considering the various condition in a single plot to show its effectiveness in vibration mitigation. The result depicts that in the presence of the passive viscous damper, the vibration reduces both in the case of displacement and acceleration when compared to uncontrolled conditions. In the presence of the MR damper, the vibration of the structure reduces more than the viscous damper. In the passive-on mode of the MR damper, the vibration is mitigated, but when this is compared with the MR damper controlled by the PID controller the vibrations 

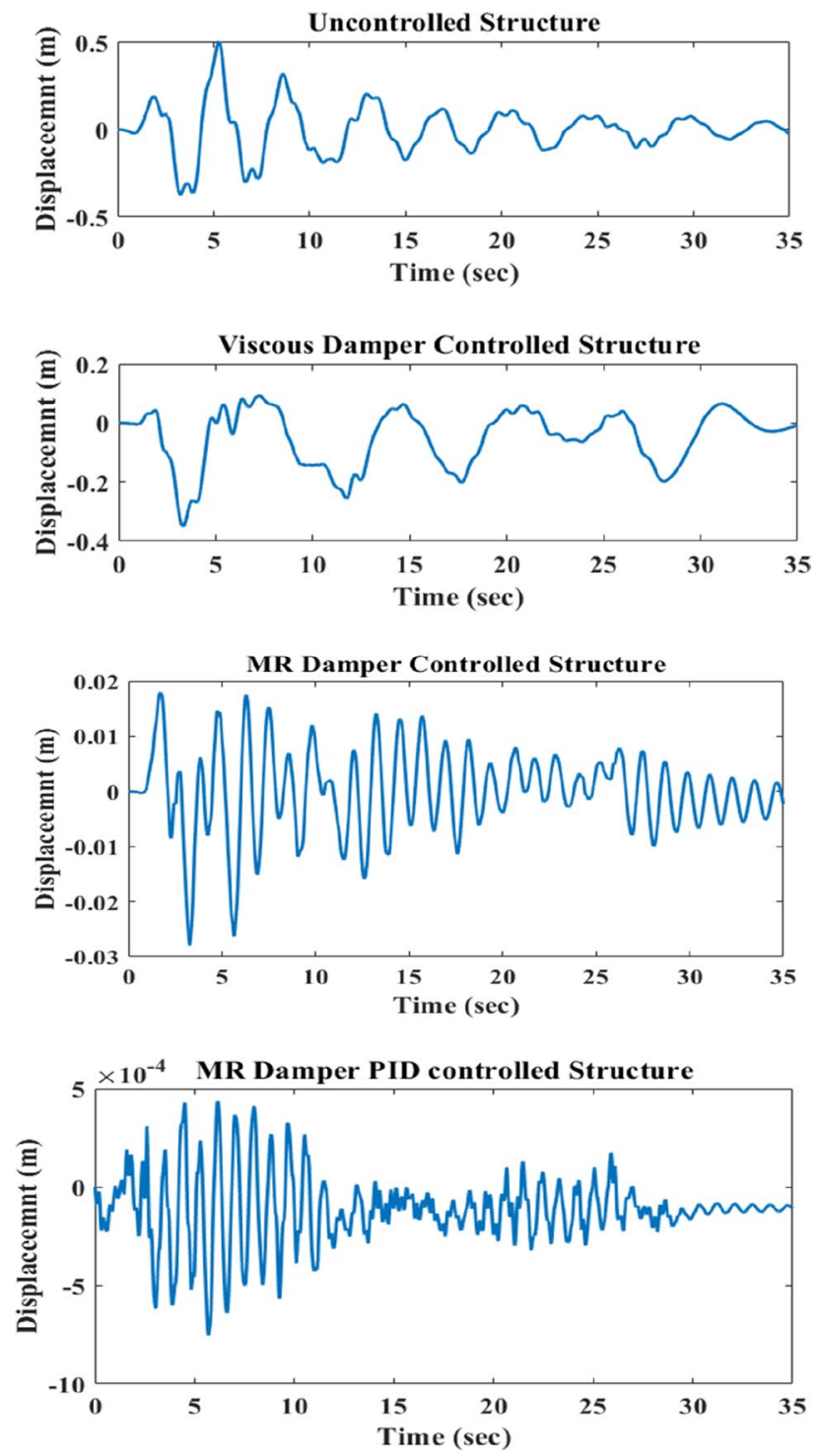

Fig. 9 Displacement profile of the top story of the outrigger structure for El-Centro earthquake

are quite reduced to the least of all the controlled conditions mentioned. Thus, the PID controlled MR damper performance is better in controlling the damped outrigger structural vibration.

The peak values of the structural response for various condition pertaining to the graph as mentioned above, are shown in Table 1 for El-Centro and Kobe earthquake. The peak value of the uncontrolled structural response is higher in amplitude for displacement and acceleration while comparing it with the controlled conditions considering the viscous damper and MR damper. The peak value of the structural response reduces with the introduction of a viscous damper, and further, the semi-active MR damper will decrease the vibration to the maximum. When the PID controller is interfaced with the MR damper, the
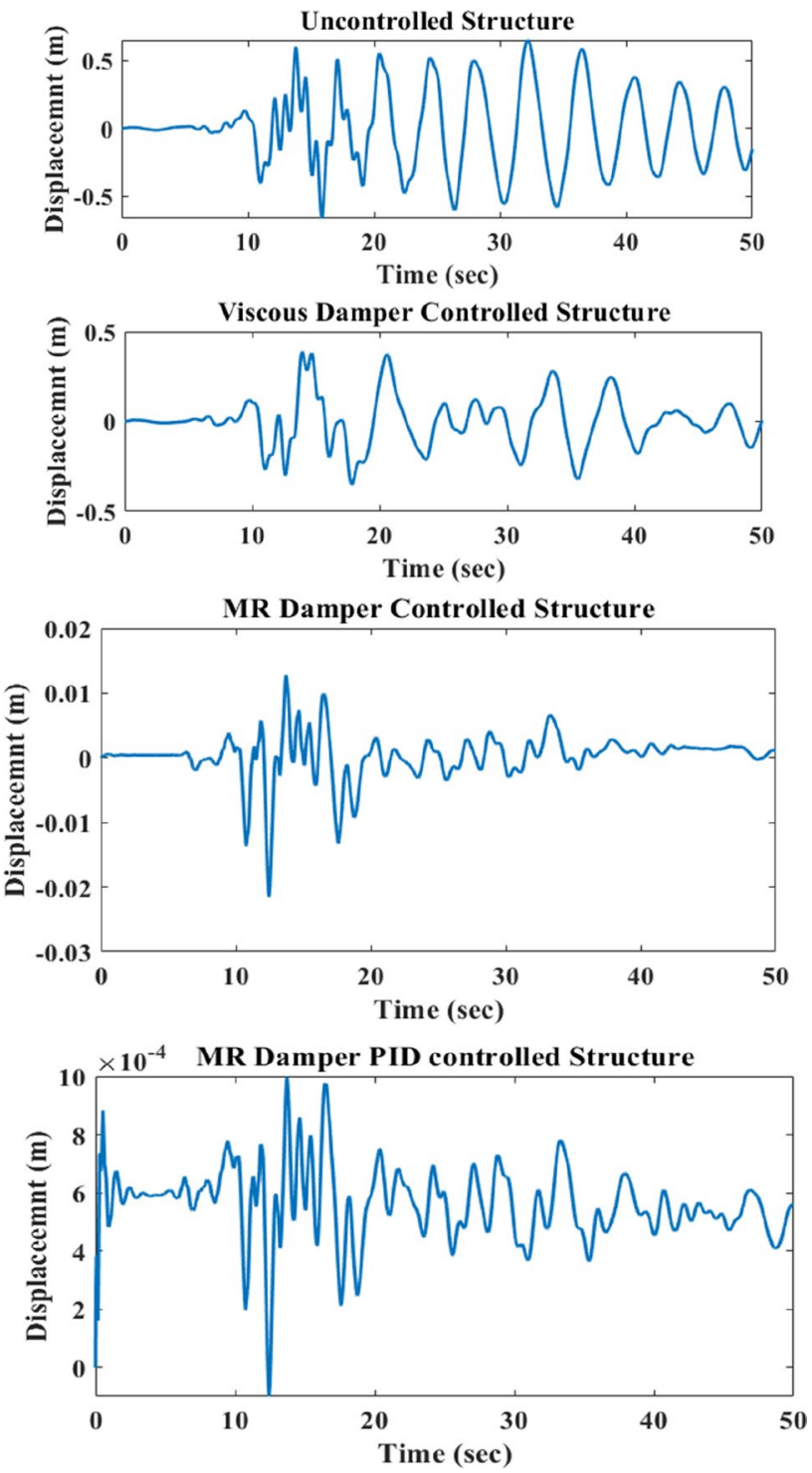

Fig. 10 Displacement profile of the top story of the outrigger structure for Kobe earthquake

response of the structure is reduced to the minimum of all the controlled and uncontrolled conditions because PID controller correlates the output feedback, integral, and derivative to the error by mitigating the response in the progressive loop. As PID controller tuning is properly done by trial and error process, it aggressively reduces the structural response in the presence of the earthquake. The mean value of the displacement and acceleration of the structure for various conditions for the El-Centro and Kobe earthquakes are shown in Table 2. The mean value displayed in the table shows that displacement and acceleration decrease for outrigger structure with damper, out of all condition the mean value is minimum for damped 

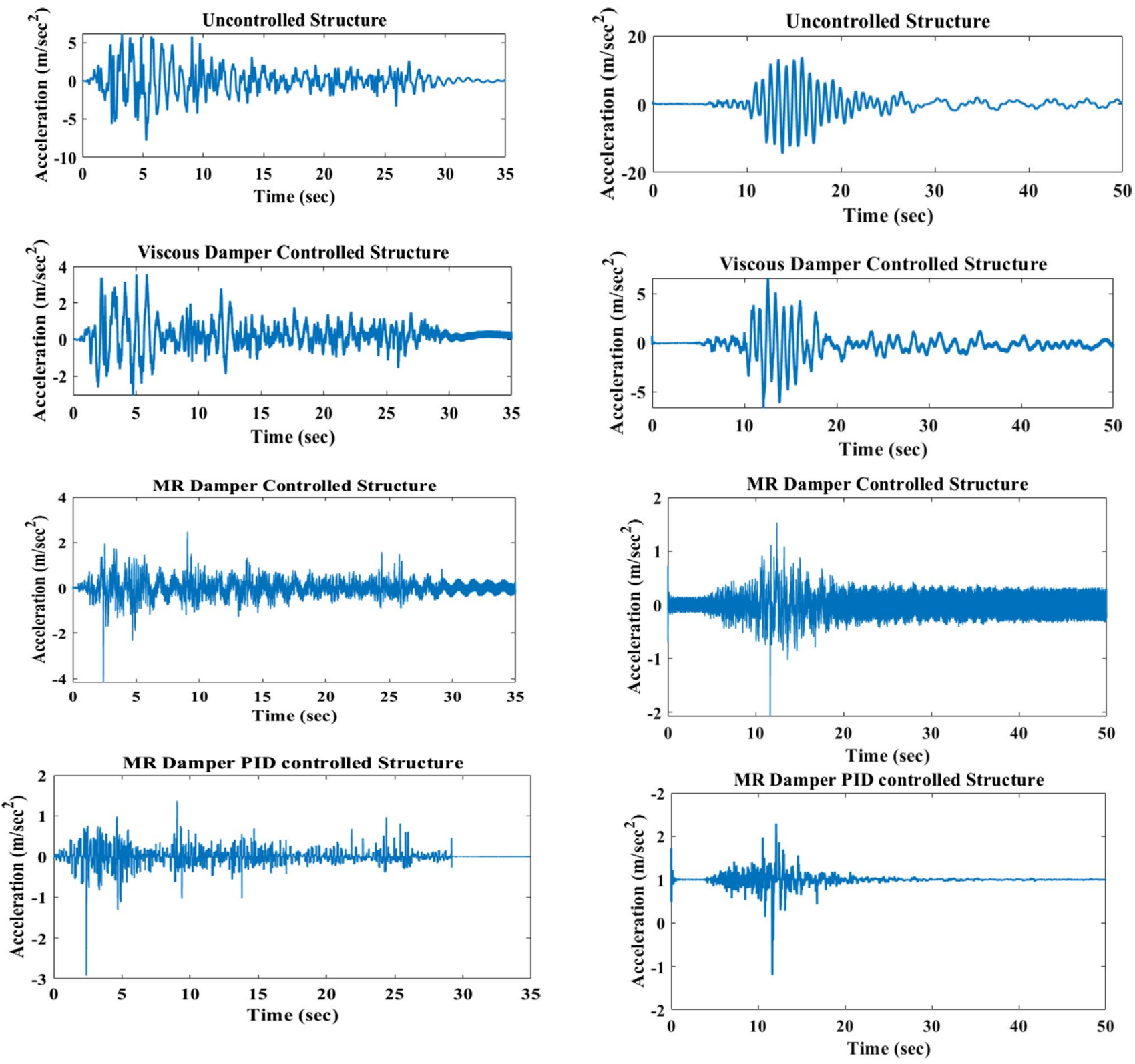

Fig. 11 Acceleration profile of the top story of the outrigger structure for El-Centro earthquake

outrigger structure controlled with MR damper regulated by PID controller.

From the tabular value, main finding of this research is reduction of the structural displacement, with the addition of viscous damper up to $50 \%$ for El-Centro earthquake and Kobe earthquake excited for the damped outrigger structure. When MR damper is used in the structural response reduction the displacement of the structure is reduced to the maximum of more than $90 \%$ for both El-Centro earthquake and Kobe earthquake. In the case of acceleration reduction,

Fig. 12 Acceleration profile of the top story of the outrigger structure for Kobe earthquake

the viscous damper controls more than $60 \%$ of the vibrations, When MR damper is used with constant current more than $80 \%$ reduction is obtained. When MR damper with PID controller is used the maximum reduction (90\%) in vibration is observed for structural acceleration. Thus, the main aim of this research of reducing the response of the structure is attained by performance enhancement of the outrigger structure with the addition of dampers with PID controller with proper tuning. 


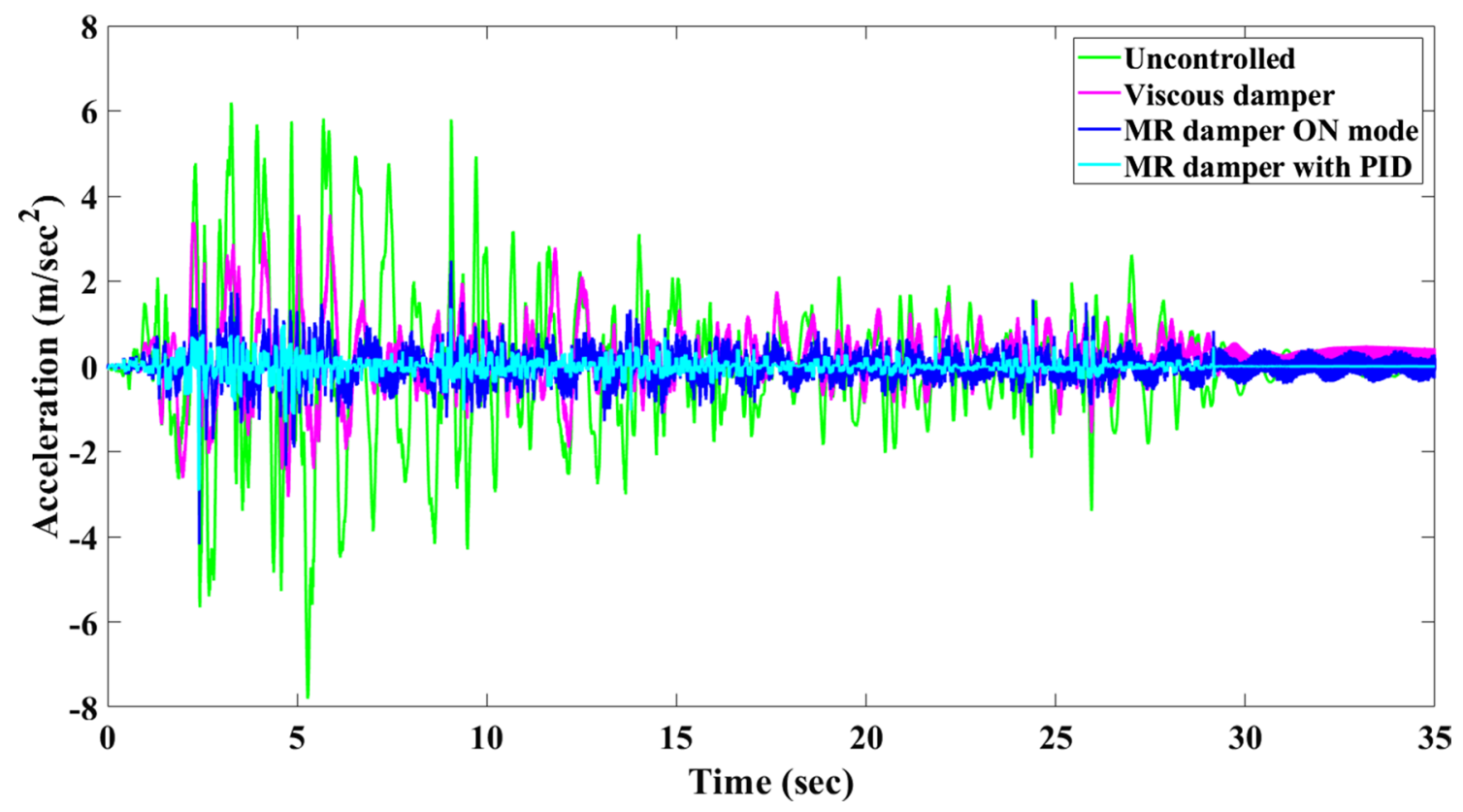

Fig. 13 Multi-variable acceleration profile for top story of the structure for El-Centro earthquake

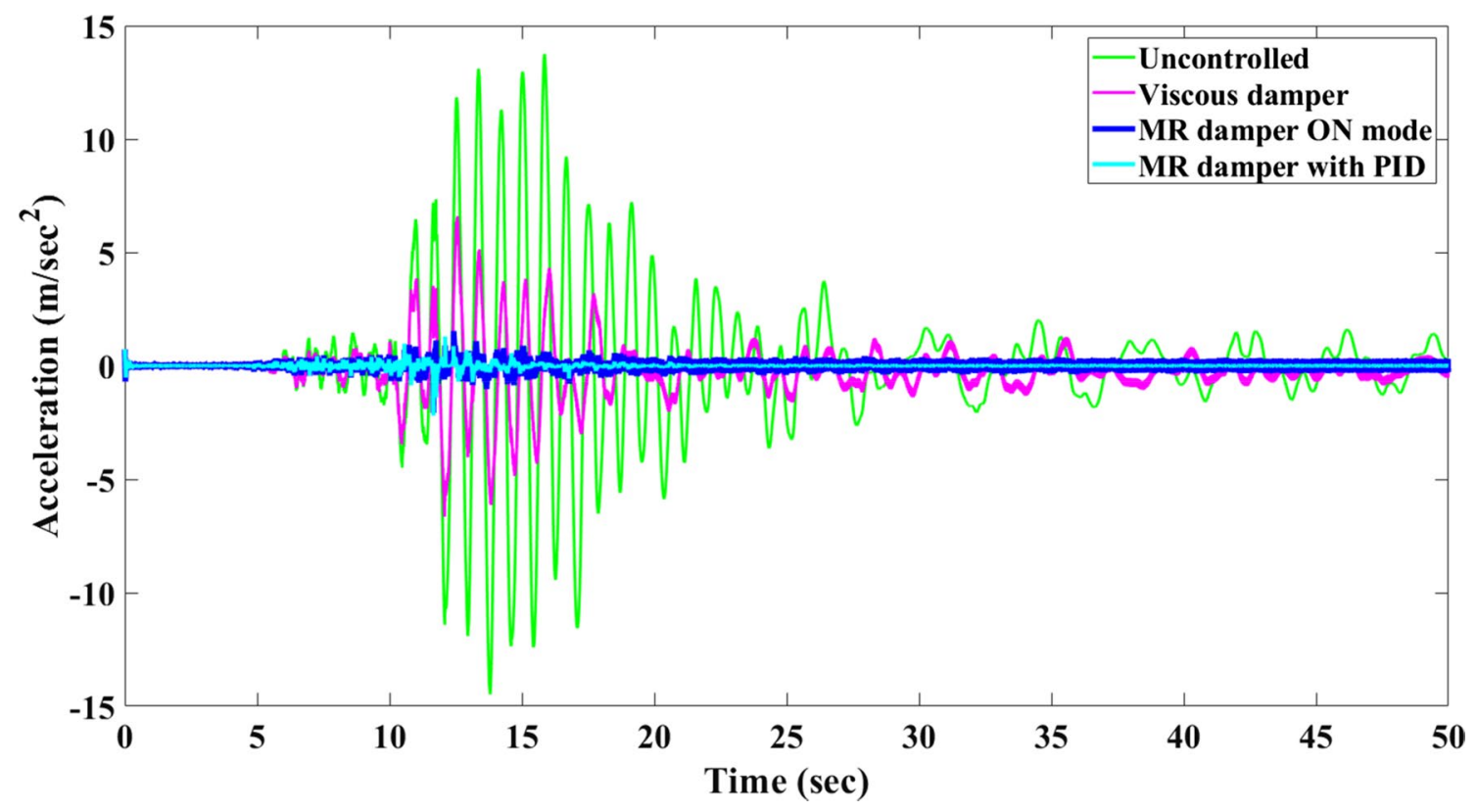

Fig. 14 Multi-variable acceleration profile for top story of the structure for Kobe earthquake

\section{Conclusions}

The damped outrigger structure replicating St. Francis Shangri-La Place Skyscraper is considered for numerical simulation excited for earthquake, is modeled using Bernoulli's Euler theory for the core of the structure using finite element approach with MATLAB and Simulink. The study aims at controlling the vibrations of the structure using the passive system as viscous damper and semi-active system as MR damper considering PID controller to regulate the damper. The damped outrigger structure is simulated to obtain uncontrolled vibration due to the earthquake, then viscous damper and MR dampers are used in mitigating the response, corresponding performance of the structure is obtained for the efficient comparison. As reported in the result section, 
Table 1 Peak value of the outrigger structural response

\begin{tabular}{lll}
\hline El-Centro Earthquake & & \\
Circumstances & Displacement $(\mathrm{m})$ & Acceleration $\left(\mathrm{m} / \mathrm{s}^{2}\right)$ \\
Uncontrolled & 0.5046 & 7.807 \\
Viscous damper Controlled & 0.3495 & 3.566 \\
MR passive-on mode & 0.028 & 4.182 \\
MR damper with PID & $7.527 \times 10^{-4}$ & 2.9224 \\
$\quad$ controller & & \\
Kobe Earthquake & & \\
Circumstances & Displacement $(\mathrm{m})$ & Acceleration $\left(\mathrm{m} / \mathrm{s}^{2}\right)$ \\
Uncontrolled & 0.66 & 14.47 \\
Viscous damper Controlled & 0.388 & 6.59 \\
MR passive-on mode & 0.022 & 2.081 \\
MR damper with PID Con- & 0.001 & 2.176 \\
$\quad$ troller & &
\end{tabular}

Table 2 Mean of the outrigger structural response

\begin{tabular}{|c|c|c|}
\hline \multicolumn{3}{|l|}{ El-Centro Earthquake } \\
\hline Circumstances & $\begin{array}{l}\text { Mean displace- } \\
\text { ment (m) for } \\
35 \mathrm{~s} \text { simula- } \\
\text { tion time }\end{array}$ & $\begin{array}{l}\text { Mean accelera- } \\
\text { tion }\left(\mathrm{m} / \mathrm{s}^{2}\right) \text { for } \\
35 \mathrm{~s} \text { simula- } \\
\text { tion time }\end{array}$ \\
\hline Uncontrolled & 0.1175 & 1.359 \\
\hline Viscous damper & 0.0564 & 0.422 \\
\hline MR-ON mode & 0.0057 & 0.261 \\
\hline MR-damper with PID Controller & 0.000173 & 0.101 \\
\hline \multicolumn{3}{|l|}{ Kobe Earthquake } \\
\hline Circumstances & $\begin{array}{l}\text { Mean displace- } \\
\text { ment (m) for } \\
50 \mathrm{~s} \text { simula- } \\
\text { tion time }\end{array}$ & $\begin{array}{l}\text { Mean accelera- } \\
\text { tion }\left(\mathrm{m} / \mathrm{s}^{2}\right) \text { for } \\
50 \mathrm{~s} \mathrm{simula-} \\
\text { tion time }\end{array}$ \\
\hline Uncontrolled & 0.1831 & 2.023 \\
\hline Viscous damper & 0.0995 & 0.672 \\
\hline MR-ON mode & 0.0022 & 0.176 \\
\hline MR-damper with PID Controller & 0.00056 & 0.032 \\
\hline
\end{tabular}

the use of the dampers and control system has shown the reduction of the structural response pertaining to the displacement and acceleration with the peak amplitude value and mean of the response. When viscous damper is attached to the structure it develops the control force opposite to the motion of the structure that shows the vibration reduction in the response from that of uncontrolled case to certain extent but not too aggressive in its action because the damping characteristic of viscous damper cannot be changed as per the requirement. Thus, a semi-active MR damper is introduced in the structure with and without PID controller and MR damper in the absence of controller with the pre-established constant voltage (passive-on mode of the MR damper) reduces the vibration to a large extent while comparing it with viscous damper control. Then PID controller is used to modify the voltage and hence control current as per the requirement of the MR damper in producing control force required by the structure in diminishing the vibration. The proposed strategy of damped outrigger structure with semiactive MR damper regulated with PID controller involves itself aggressively in mitigation of the structural response to a minimum range. The use of the PID controller in computing the required voltage has functioned predominantly in producing required force by MR damper against the earthquake force striking the structure. In this paper, the damped outrigger structural performance enhancement has been achieved by using the semi-active controller. Installation of the smart protective system in structures is still an upcoming practice, but it has huge potential in structural health monitoring and structural control.

Acknowledgements We would like to thank the Manipal Academy of Higher Education, Manipal, Karnataka, India for all the support provided.

Funding Open access funding provided by Manipal Academy of Higher Education, Manipal.

\section{Declarations}

Conflict of interest On behalf of all authors, the corresponding author states that there is no conflict of interest.

Open Access This article is licensed under a Creative Commons Attribution 4.0 International License, which permits use, sharing, adaptation, distribution and reproduction in any medium or format, as long as you give appropriate credit to the original author(s) and the source, provide a link to the Creative Commons licence, and indicate if changes were made. The images or other third party material in this article are included in the article's Creative Commons licence, unless indicated otherwise in a credit line to the material. If material is not included in the article's Creative Commons licence and your intended use is not permitted by statutory regulation or exceeds the permitted use, you will need to obtain permission directly from the copyright holder. To view a copy of this licence, visit http://creativecommons.org/licenses/by/4.0/.

\section{References}

1. Smith RJ (2011) Deflection limits in tall buildings - Are they useful? Struct Con Las Vegas, Nevada, US. https://doi.org/10.1061/ 41171(401)45

2. Chopra AK (2001) Dynamics of structures: theory and applications to earthquake engineering, 2nd edn. Prentice Hall, Upper Saddle River, NJ

3. Spencer BF, Nagarajaiah S (2003) State of the art of structural control. J Struct Eng 129(7):845-856. https://doi.org/10.1061/ (ASCE)0733-9445(2003)129:7(845)

4. Smith B, Coull A (1991) Tall building structures: analysis and design. Wiley, New York, USA

5. Choi H, Ho G, Joseph L, Mathias N (2012) Outrigger design for high rise buildings. An output of the CTBUH outrigger working Group, Council on Tall Buildings and Urban Habitat: Chicago 
6. Smith RJ, Willford MR (2008) Damping in tall buildings - uncertainties and solutions. International Association for Bridge and Structural Engineering, Chicago

7. Smith BS, Salim I (1981) Parameter Study of Outrigger-Braced Tall Building Structures. J Struct Div 107(10):2010-2014

8. Lin PC, Takeuchi T, Matsui R (2019) Optimal design of multiple damped-outrigger system incorporating buckling-restrained braces. Eng Struct 194:441-457

9. Lin PC, Takeuchi T, Matsui R (2018) Seismic performance evaluation of single damped outrigger system incorporating buckling restrained braces. Earthqu Eng Struct Dyn 47(12):1-23

10. Lin PC, Takeuchi T (2019) Seismic performance of bucklingrestrained brace outrigger system in various configurations. Jpn Archi Rev 2(4):392-408. https://doi.org/10.1002/2475-8876. 12120

11. Ping T, Chuangjie F, Fulin Z (2014) Dynamic characteristics of a novel damped outrigger system. Earthquake Eng Eng Vibr 13:293-304. https://doi.org/10.1007/s11803-014-0231-3

12. Asai T, Ikago K, Araki Y (2015) Outrigger tuned viscous mass damping system for high-rise buildings subject to earthquake loadings. In: Proceedings of 6th international conference on advances in experimental structural engineering, University of Illinois, Urbana-Champaign, United States

13. Smith R (2016) The damped outrigger - design and implementation. Int J High-Rise Build 5(1):63-70

14. Morales BM, Turan G, Dursun O, Nijsse R (2018) Energy dissipation and performance assessment of double damped outriggers in tall buildings under strong earthquakes. Struct Des Tall Spec Build 28(1):e1554. https://doi.org/10.1002/tal.1554

15. Morales BM, Turan G, Yildirim U, Paul J (2018) Distribution of strong earthquake input energy in tall buildings equipped with damped outriggers. Struct Des Tall Special Build 27(8):e1463. https://doi.org/10.1002/tal.1463

16. Chang CM, Wang Z, Spencer BF Jr, Chen Z (2010) Controllable outrigger damping system for higher-rise buildings with MR dampers. Sens Smart Struct Technol Civ Mech Aerosp Syst. https://doi.org/10.1117/12.847837

17. Smith RJ, Willford MR (2007) The damped outrigger concept for tall buildings. Struct Des Tall Special Build 16:501-517. https:// doi.org/10.1002/tal.413

18. Chang CM, Wang Z, Spencer BF Jr, Chen Z (2013) Semi-active damped outriggers for seismic protection of high-rise buildings. Smart Struct Syst 11(5):435-451

19. Xing L, Zhou Y, Aguaguina M (2018) Optimal vertical configuration of combined energy dissipation outriggers. Struct Des Tall Spec Build 28(4):e1579. https://doi.org/10.1002/tal.1579
20. Willford MR, Smith RJ (2008) Performance based seismic and wind engineering for 60 story Twin Towers in Manila. In: The 14th world conference on earthquake engineering, Beijing, China, October

21. Chen Y, McFarland DM, Wang Z, Spencer BF, Bergman LA (2010) Analysis of tall buildings with damped outriggers. J Struct Eng 136(11):1435-1443

22. Peng Y, Zhang Z (2020) Optimal MR damper-based semi-active control scheme for strengthening seismic capacity and structural reliability. J Eng Mech 146(6):04020045-04020051

23. Fang C, Spencer BF, Xu J, Tan P, Zhou F (2019) Optimization of damped outrigger systems subject to stochastic excitation. Eng Struct 191:280-291. https://doi.org/10.1016/j.engstruct.2019.04. 011

24. Asai T, Chang CM, Phillips BM, Spencer BF (2013) Real-time hybrid simulation of a smart outrigger damping system for highrise buildings. Eng Struct 57:177-188

25. Gamaliel R (2007) Frequency-based response of damped outrigger systems for tall buildings. Dissertation, Massachusetts Institute of Technology, USA

26. Wang M, Nagarajaiah S, Sun FF (2020) Dynamic characteristics and responses of damped outrigger tall buildings using negative stiffness. J Struct Eng 146(12):04020273-04020281

27. Cruze D, Gladston H, Farsangi EN, Banerjee N, Loganathan S, Solomon SN (2020) Seismic performance evaluation of a recently developed magnetorheological damper: experimental investigation. Pract Period Struct Des Constr 26(1):04020061-04020071

28. Spencer B, Dyke S, Sain M (1997) Phenomenological model for magneto-rheological dampers. J Eng 123(3):230-238. https://doi. org/10.1061/(ASCE)0733-9399(1997)123:3(230)

29. Yang G, Spencer BF, Carlson JD, Sain MK (2002) Large-scale MR fluid dampers: modeling and dynamic performance considerations. Eng Struct 24(3):309-323

30. Dyke SJ, Spencer BF, Sain MK, Carlson JD (1996) Modeling and control of magnetorheological dampers for seismic response reduction. Smart Mater Struct 5(5):565-575

31. Guclu R (2006) Sliding mode and PID control of a structural system against earthquake. Math Comput Model 44:210-217. https:// doi.org/10.1016/j.mcm.2006.01.014

32. Ogata K (2011) Modern Control Engineering. $5^{\text {th }}$ edition, Pearson education 